\title{
Monitoring trends in sea turtle populations: walk or fly?
}

\author{
Melissa L. Warden ${ }^{1}$, Heather L. Haas ${ }^{2}$, Paul M. Richards ${ }^{3}$, Kenneth A. Rose ${ }^{4}$, \\ Joshua M. Hatch ${ }^{1, *}$ \\ ${ }^{1}$ Integrated Statistics, Woods Hole, MA 02543, USA \\ ${ }^{2}$ Northeast Fisheries Science Center, NOAA National Marine Fisheries Service, Woods Hole, MA 02543, USA \\ ${ }^{3}$ Southeast Fisheries Science Center, NOAA National Marine Fisheries Service, Miami, FL 33149, USA \\ ${ }^{4}$ Horn Point Laboratory, University of Maryland Center for Environmental Science, PO Box 775, Cambridge, MD 21613, USA
}

\begin{abstract}
Monitoring animal populations is essential to conservation, and complex monitoring goals require complex resources. Variable detection probabilities can create uncertainty in trends and abundances estimated from point count surveys (e.g. nest counts), as well as from more expensive monitoring methods such as line transect surveys (e.g. aerial surveys). Point count surveys in the form of nest counts are the most common form of sea turtle population monitoring, although in-water aerial surveys are also conducted. We used a loggerhead sea turtle Caretta caretta population model to generate stochastic 'known' populations from which we mimicked the information we would obtain from nest counts and from in-water aerial surveys. We subjected the populations to environmental or anthropogenic impacts and compared trends in each monitoring metric with the trend in simulated turtle population size in terms of adult equivalents. Over long time frames, either monitoring scheme performed equally well (mean population growth rates $\lambda$ over 50 yr were within $1 \%$ of the growth rate estimated from simulated adult equivalents). Over shorter time frames, total adult females estimated from simulated nest counts generally tracked closer to adult equivalents than did abundance estimated from simulated aerial surveys; and $\lambda$ for the nest count metric generally had a lower median absolute relative error. Aerial surveys added value if population impacts affected young turtles (which can take 20-30 yr to become nesters) or if impacts changed the population structure (e.g. changed the stable age distribution). For effective monitoring over short time frames, both monitoring schemes might be warranted.
\end{abstract}

KEY WORDS: Loggerhead $\cdot$ Caretta caretta $\cdot$ Nest counts $\cdot$ Line transect survey $\cdot$ Simulation $\cdot$ Abundance index $\cdot$ Adult equivalent

\section{INTRODUCTION}

Monitoring animal populations is an essential but challenging component of wildlife stewardship, and the resources required for effective monitoring often increase with the complexity of the goals. Monitoring goals (in order of increasing complexity) can include establishing occupancy, determining population trends, and estimating total abundance.

${ }^{*}$ Corresponding author: joshua.hatch@noaa.gov
Where limited resources prevent gathering sufficient data to address complex goals, it has been suggested that simple point-count surveys can successfully monitor population trend as long as the detection probability (i.e. the ratio of the raw count to the total abundance) is relatively constant across space and time (Engeman 2003, Bart et al. 2004). Other research suggests that trend or abundance estimates based on point counts will always be

(C) Outside the USA the US Government 2017. Open Access under Creative Commons by Attribution Licence. Use, distribution and reproduction are unrestricted. Authors and original publication must be credited.

Publisher: Inter-Research · www.int-res.com 
biased because constant detectability is unlikely given that detectability can be affected by so many factors. These factors include environmental conditions (e.g. wind, precipitation, season, time of day, glare, and habitat type); observer characteristics such as experience, training, eyesight, and fatigue; and study animal characteristics such as their color, behavior, and group size (Anderson 2001, Thompson 2002).

Distance sampling methods, such as line transect surveys, are designed to include such heterogeneity (Buckland et al. 2001). Random placement of transect lines can account for spatial variability in animal density, and detection probabilities are determined in relation to distance from the transect line. Failure to detect animals on the transect line can be categorized as perception bias, when animals could potentially be seen or heard but are missed by observers, or availability bias, when animals are present but are not available to be seen or heard by observers. Availability bias can arise when animals are under dense cover or underwater, or are quiet during a mostly aural survey. Abundance estimates will be negatively biased if perception bias and availability bias are inherent in the data but are not incorporated into the analysis (Marsh \& Sinclair 1989, Laake \& Borchers 2004, Borchers et al. 2013, Borchers \& Langrock 2015).

Counting reproductive females can be a preferred population-monitoring approach because female vital rates typically determine population dynamics (e.g. female-only demographic models, Caswell 2001). For sea turtles, nest counts can provide an index of reproductive females, and surveying of nests on beaches is the most common form of sea turtle population monitoring (Sims et al. 2006, Witherington et al. 2009, Whiting et al. 2014). Beach surveys are easier and less expensive than in-water aerial surveys or mark-recapture studies, and the sampling error is relatively low (Witherington et al. 2009). Monitoring of nesting also provides useful information on productivity (e.g. nesting rates and hatching success) (Ehrhart et al. 2014).

Nest counts, however, are not a perfect population index. Nesting females have the highest future reproductive potential (i.e. reproductive value) (Wallace et al. 2008), but they make up a small segment of the total population (Chaloupka 2003), and nest counts provide little information about juvenile life stages or population structure. Also, females do not generally nest every year, and they generally nest more than once each nesting season. Therefore, nest counts reflect only that year's nesters (Chaloupka \& Limpus 2001), who may have laid $>1$ clutch. Depend- ing on species, estimated annual clutch frequencies range from 1 to 8 nests (Carr et al. 1978, TEWG 1998, 2000, SEFSC 2009, Frey et al. 2014), and estimated mean remigration intervals (i.e. the number of years from one nesting season to the next) range from 1 to 5 yr (TEWG 1998, 2000, Tro $\lambda$ ng \& Chaloupka 2007, SEFSC 2009, Seminoff et al. 2015) or more (Piacenza et al. 2016). Variability in remigration interval and clutch frequency adds uncertainty in translating nest counts to the number of adult females. For example, 4 clutches $\mathrm{yr}^{-1}$ and a 2 yr remigration interval would correspond to 4000 total adult females per 10000 nests; 5 clutches and a $3 \mathrm{yr}$ remigration interval would correspond to nearly double the total estimated adult females (7500).

In-water aerial surveys for turtles (Epperly et al. 1995, Mansfield 2006, Lauriano et al. 2011, NEFSC \& SEFSC 2011) have the potential to monitor more demographic information, including juveniles as small as $30 \mathrm{~cm}$ long (Epperly et al. 1995). However, the National Marine Fisheries Service (NMFS) does not currently collect information on turtle sizes during aerial surveys, with aerial surveys providing an aggregate measure of abundance over multiple stage classes. Part of the trade-off is that aerial surveys are more expensive than nest counts and require highly specialized observers. Also, the low population density of turtles over large areas makes it difficult to estimate detection rates without pooling observations across seasons or species (Bovery \& Wyneken 2015), and, without precise detection rates, results in abundance estimates with high uncertainty (Buckland et al. 2001).

The most common sea turtle monitored along the US Atlantic coast is the loggerhead Caretta caretta. The Northwest (NW) Atlantic Ocean Distinct Population Segment (DPS) is protected as threatened under the US Endangered Species Act (ESA), and peninsular Florida contains about $80 \%$ of the nests for this DPS (TEWG 2009). The Florida Index Nesting Beach survey counts about $70 \%$ of the total nesting in the state and has been in place since 1989 (Witherington et al. 2009). Since 1983, in-water data on sea turtles and marine mammals have also been collected (Thompson 1986); such monitoring was intensified after 2010 by US government partners to support an Atlantic Marine Assessment Program for Protected Species (AMAPPS). As part of the AMAPPS project, as well as historic US NMFS projects, millions of dollars have been spent on line transect aerial surveys for protected species, including sea turtles. The utility of these flights for loggerhead population monitoring is uncertain because of the high variability of abundance 
estimates and the uncertainty around loggerhead availability bias. Because loggerheads dive deep below the water's surface for as long as several hours (Hawkes et al. 2007), line transect methods may be unacceptably biased for loggerheads without robust estimates of availability (Thomson et al. 2012, 2013).

Effective population monitoring is important for determining if ESA recovery goals have been met, for detecting anthropogenic or environmental impacts that might affect the population, and for regulating marine industry whose activities can impact the turtles. Anthropogenic impact can include oil spills (Bjorndal et al. 2011), habitat degradation (Bjorndal et al. 1994, Fish et al. 2005), and incidental bycatch in commercial fishing operations (Finkbeiner et al. 2011, Murray 2015). NMFS is responsible for determining whether any marine activity, including commercial fishing activity, is likely to negatively impact the loggerhead population, and NMFS' actions to recover sea turtles could have economic impact on the fishing industry (Curtis \& Hicks 2000, Magnusson et al. 2012).

In this paper, we use a simulation approach to evaluate nest counts and line-transect aerial surveys as loggerhead sea turtle population monitoring metrics. We focused on nest counts and aerial surveys, as the NMFS currently uses both to monitor the NW Atlantic loggerhead DPS (TEWG 2009, NEFSC \& SEFSC 2011), although this should not preclude future consideration of other approaches (e.g. mark-recapture). We use an established loggerhead population dynamics model (Warden et al. 2015) to generate simulated population trajectories, and we mimic sampling of nests that we then translate to total adult females based on estimates of remigration interval and clutch frequency. We also mimic aerial survey abundance estimates by adding estimated sampling error to simulated abundance. We compare the determined trends in simulated monitoring metrics (nest counts, aerial surveys) to the trends in total simulated adult equivalent loggerheads. This approach treats the model-generated population dynamics as the true virtual population, and thus we used the model-simulated results to evaluate the accuracy and precision of the simulated monitoring.

\section{METHODS}

\section{Population model}

We simulated female-only population dynamics using the hybrid age/stage-classified, 3-region matrix model described in Warden et al. (2015). The mod- eled population had 4 life stages: (1) hatchlings and oceanic juveniles, (2) small juveniles, (3) large juveniles, and (4) adults. The model's parameter values were stage-based, but to allow for long time lags during population projection, the model's structure was age-classified. We formed age classes within stages, and we assigned identical parameter values to all ages within a stage. The model's 3 regions represented foraging habitats off the US Atlantic coast: neritic north $\left(\mathrm{NN}_{\text {; }}\right.$ on the continental shelf and $>34^{\circ} \mathrm{N}$ ), neritic south (NS), and oceanic (off the continental shelf). All combinations of movement between any 2 regions were possible through a stagebased movement matrix that was combined with regional survival and reproduction matrices to form an overall projection matrix A (see Warden et al. 2015 for details).

\section{Stochastic demographic vital rates}

We used the same vital rates (Table 1) as Warden et al. (2015) (based on SEFSC 2009), and we introduced stochasticity using variances that resulted in parameter ranges similar to those given in SEFSC (2009). Variances were based on sources reported in SEFSC (2009) or on more recent literature (Hart et al. 2013). We separated variances into $50 \%$ sampling variance (e.g. measurement error) and $50 \%$ process variance (e.g. environmental stochasticity).

To produce stochastic vital rates, we first generated a simulation-level mean $\left(\mu_{i}\right)$ and a simulation-level standard deviation $\left(\sigma_{i}\right)$ for each vital rate in each of $i$ simulations. Simulation-level means were drawn from a uniform distribution or a stretched beta distribution (i.e. a rescaled beta distribution with minimum and maximum values other than 0 and 1 ) so that we could specify lower and upper bounds. Table 1 shows the distribution for each vital rate. Input parameters for a uniform distribution on interval $[a, b]$ were $a=\operatorname{Min}(3)$ and $b=\operatorname{Max}(4)$, where numbers in parentheses indicate the column in Table 1. Input parameters from Table 1 for a stretched beta distribution on interval $[a, b]$ were mean $=$ Mean $(2)$, standard deviation $=\mathrm{SD}_{\mathrm{s}}(6), a=\operatorname{Min}(3)$, and $b=\operatorname{Max}(4)$. Simulation-level standard deviations $\left(\sigma_{i}\right)$ were drawn from an inverse gamma distribution with the mean $=\mathrm{SD}_{\mathrm{p}}$ (Table 1: 7) and the standard deviation based on a $5 \%$ coefficient of variation (CV).

Annual realizations of vital rates $\left(\mu_{i j}\right.$, where $j=$ year 1-100) were drawn from beta distributions with the mean $=\mu_{i}$ and the standard deviation $=\sigma_{i,}$ or from stretched beta distributions on interval $[a, b]$ with 
Table 1. Vital rates with their distributions (Dist.) and parameter estimates (mean, minimum, maximum, standard deviation [SD]). Columns are numbered for easy reference, $\mathrm{SD}_{\mathrm{s}}=$ square root of sampling variance, $\mathrm{SD}_{\mathrm{p}}=$ square root of process variance, $\mu_{i}=$ mean for simulation $i, \mu_{i j}=$ mean for year $j$ of simulation $i$, na $=$ not applicable. Stage durations are in years. See Supplement 2 for stochastic remigration intervals

\begin{tabular}{|c|c|c|c|c|c|c|c|c|}
\hline$(1)$ & $(2)$ & (3) & $(4)$ & $(5)$ & (6) & (7) & (8) & (9) \\
\hline Vital rate & Mean & Min & Max & $\mathrm{SD}$ & $\mathrm{SD}_{\mathrm{s}}$ & $\mathrm{SD}_{\mathrm{p}}$ & Dist. of $\mu_{i}$ & Dist. of $\mu_{i j}$ \\
\hline Stage 1 duration & 13 & 10 & 18 & & & & Uniform & na \\
\hline Stage 2 duration & 10 & 9 & 12 & & & & Uniform & na \\
\hline Stage 3 duration & 7 & 4 & 12 & & & & Uniform & na \\
\hline Stage 1 survival & 0.744 & 0.588 & 0.878 & 0.060 & 0.042 & 0.042 & Stretched beta & Beta \\
\hline Stage 2 survival & 0.830 & 0.740 & 0.890 & 0.035 & 0.025 & 0.025 & Stretched beta & Beta \\
\hline Stage 3 survival & 0.835 & 0.740 & 0.925 & 0.035 & 0.025 & 0.025 & Stretched beta & Beta \\
\hline Stage 4 survival & 0.841 & 0.770 & 0.925 & 0.035 & 0.025 & 0.025 & Stretched beta & Beta \\
\hline Nests per female & 5 & 2 & 8 & 1.3 & 0.919 & 0.919 & Stretched beta & Stretched beta \\
\hline Eggs per nest & 109 & 89 & 125 & 10 & 7.071 & 7.071 & Stretched beta & Stretched beta \\
\hline Egg survival & 0.53 & 0.11 & 0.82 & 0.10 & 0.071 & 0.071 & Stretched beta & Beta \\
\hline Proportion female & 0.50 & 0.35 & 0.80 & 0.07 & 0.049 & 0.049 & Stretched beta & Beta \\
\hline
\end{tabular}

mean $=\mu_{i}$, standard deviation $=\sigma_{i}, a=$ Min $($ Table 1 : 3), and $b=$ Max (Table 1: 4). Table 1 shows which distribution was used for each vital rate. Stage durations were constant within a simulation so all $\mu_{i j}=\mu_{i}$. Movement probabilities between the 3 regions were also drawn annually from a beta distribution with mean equal to the movement probabilities in Warden et al. (2015) and small standard deviations $(\leq 0.01)$. The variability in movement probabilities matched biological expectations, and prior work showed that long-term population growth rates were relatively insensitive to differences in movement among regions (Warden et al. 2015). See Supplement 1 at www.int-res.com/articles/suppl/n034p323_supp.pdf for examples of sampled vital rates and movement distributions.

Correlated survival rates for stages 1-4 were achieved by first generating correlated values from a multivariate standard normal distribution and then applying the probability integral transformation to get correlated values from the beta or stretched beta distribution (Morris \& Doak 2002). Correlations are given in Table 2.

For remigration intervals (i.e. the number of years between breeding events), we created annual realizations by choosing from 23 possible sets of probabilities for remigrating in 1, 2, 3, 4, or 5 yr (Supplement 2). Each year, a column from Table S1 (in

Table 2. Correlations between stage-specific survival rates

\begin{tabular}{|cccc|} 
& Stage 1 & Stage 2 & Stage 3 \\
\hline Stage 2 & 0.1 & & \\
Stage 3 & 0.1 & 0.8 & \\
Stage 4 & 0 & 0.6 & 0.8 \\
\hline
\end{tabular}

Supplement 2) was drawn using a uniform distribution. The mean remigration interval ranged from 2.74 to 3.65 , with an overall mean of 3.03 .

If the randomly selected combination of simulation-level or annual vital rates resulted in a projection matrix (as described below in 'Projection matrices and population projection') with a dominant eigenvalue $\lambda$ (i.e. population growth rate) that was $<0.9$ or $>1.1$, a new combination of vital rates was drawn (Snover \& Heppell 2009). We rejected these combinations because they resulted in unrealistically low or high annual population growth rates.

\section{Impact scenarios}

Table 3 describes 6 scenarios in which specific vital rates were perturbed to represent environmental or anthropogenic impact. The impacts were designed to roughly represent catastrophes (such as an oil spill), development of a new fishery, an additional threat to stage 1 , more nests per female or a longer remigration interval than assumed, and conservation measures that would increase survival. Impact scenarios were applied to the annual vital rates after the rates were adjusted for stochasticity.

\section{Projection matrices and population projection}

We constructed annual projection matrices as described in Warden et al. (2015). The number of female loggerheads in the population at year $t$ was projected annually by

$$
\mathbf{n}(t+1)=\mathbf{A n}(t)
$$


Table 3. Six impact scenarios and the vital rates affected (marked with ' $x$ '). NN: neritic north, NS: neritic south

\begin{tabular}{|c|c|c|c|c|c|c|c|c|}
\hline Scenario & $\begin{array}{l}\text { Stage } 1 \\
\text { survival }\end{array}$ & $\begin{array}{l}\text { Stage } 2 \\
\text { survival }\end{array}$ & $\begin{array}{l}\text { Stage } 3 \\
\text { survival }\end{array}$ & $\begin{array}{c}\text { Stage } 4 \\
\text { survival }\end{array}$ & Fecundity & Remigration & $\begin{array}{l}\text { Regions } \\
\text { affected }\end{array}$ & Effect \\
\hline Catastrophe & $\mathrm{x}$ & $\mathrm{x}$ & $\mathrm{x}$ & $\mathrm{x}$ & $\mathrm{x}$ & & NS & $\begin{array}{l}\text { Reduced by } 40 \% \text { in year } 11 \text {; effect } \\
\text { gradually lessens over next } 5 \text { yr so } \\
\text { that no effect by year } 17\end{array}$ \\
\hline New fishery & & $\mathrm{x}$ & $\mathrm{x}$ & $\mathrm{x}$ & & & NN, NS & Reduced by $25 \%$ for years 11 and on \\
\hline $\begin{array}{l}\text { Threat to } \\
\text { stage } 1\end{array}$ & $\mathrm{x}$ & & & & & & All & Reduced by $40 \%$ for years $11-50$ \\
\hline $\begin{array}{l}\text { More nests per } \\
\text { female (i.e. } \\
\text { more clutches) }\end{array}$ & & & & & $\mathrm{x}$ & & All & $\begin{array}{l}\text { Nests per female gradually in- } \\
\text { creased by } 50 \% \text { over } 60 \text { yr starting } \\
\text { at year } 11 \text {, then stabilized at } \\
\text { higher level }\end{array}$ \\
\hline $\begin{array}{l}\text { Longer } \\
\text { remigration }\end{array}$ & & & & & & $\mathrm{x}$ & All & $\begin{array}{l}\text { From year } 11 \text { on, average remigra- } \\
\text { tion interval is } 4.5 \mathrm{yr} \text { instead of } 3 \mathrm{yr}\end{array}$ \\
\hline $\begin{array}{l}\text { Conservation } \\
\text { measure }\end{array}$ & & $\mathrm{x}$ & $\mathrm{x}$ & $\mathrm{x}$ & & & All & $\begin{array}{l}\text { Gradually increased by } 3 \% \text { over } \\
10 \text { yr starting at year } 11 \text {, then } \\
\text { stabilized at increased level }\end{array}$ \\
\hline
\end{tabular}

where $\mathbf{n}(t)$ is the abundance vector and $\mathbf{A}$ is the projection matrix. Initial abundance was based on aerial survey abundance estimates (NEFSC \& SEFSC 2011) and abundance was projected for 100 yr. Modelpredicted populations consisted of the annual abundances of hatchlings and oceanic juveniles, small juveniles, large juveniles, and adults for each of the 3 spatial regions. Drawing of stochastic vital rates, construction of projection matrices, perturbation through impact scenarios, and population projection (stage abundance by region) was repeated for 10000 simulations per impact scenario.

\section{Adult equivalents}

As a measure of the simulated 'true' abundance, we considered the model-generated total population abundance in terms of adult equivalents. Adult equivalents represent the contributions that individuals make to current and future reproduction (Fisher 1930), and they transform the 'value' of all age classes to the same scale. When considering population impact to sea turtles, the population is better represented by life stage abundances or in terms of total adult equivalents (Haas 2010, Warden et al. 2015). We calculated adult equivalent turtles by multiplying the projected annual abundance vectors by the vector of reproductive values (RVs). The age-based RVs were determined using the left eigenvector of the average projection matrix $\overline{\mathbf{A}}_{i}$ (Lande \& Orzack 1988, Morris \& Doak 2002), where $i$ is the simulation. RVs did not vary annually. RVs were scaled so that they were near 0 for the youngest turtles and they were 1 for breeding adults. Thus, 1 breeding adult $=1$ adult equivalent.

The average projection matrix $\overline{\mathbf{A}}_{i}$ that we used for calculating RVs for each simulation $i$ was taken from the population for simulation $i$ with no impact scenario applied. We used those same RVs across all impact scenarios. We realized that RVs may be affected by changing environmental conditions (e.g. RVs are affected by survival and fecundity values, Heppell 2005), and to explore this, we tested using different $\overline{\mathbf{A}}_{i}$ s for each impact scenario. This approach was problematic, however, because the simulated anthropogenic or environmental impacts affected the population over specific timeframes, but the RVs were calculated as an average over the entire $100 \mathrm{yr}$. For years before the impact or after its end, the average RVs were different from what the unaffected matrices for those years would produce. This led us to explore using RVs that varied annually, i.e. they were calculated from the annual $\mathbf{A}_{i j}$ matrices, where $j=$ year, instead of the average matrix $\overline{\mathbf{A}}_{i}$. This approach had greater variability in the number of adult equivalents that were estimated annually, which might better represent the effects of changing population dynamics, but it was subject to modeling effects from the eigenvalue analysis that were not reflective of what would be happening in nature. Therefore, we used the average 'no-impact' RVs for all impact scenarios within a simulation. All 3 of the methods resulted in similar average patterns for the total number of adult equivalents. (See Supplement 3 for examples of using the impact-specific average or annual RVs.) 


\section{Sampling 'survey' data}

We mimicked sampling from 2 types of field surveys: nest counts and in-water aerial surveys. Nest counts were extrapolated to total adult females based on productivity parameters (Snover \& Heppell 2009), and we mimicked abundance estimates derived from aerial surveys. To generate the monitoring survey data, we applied simulated sampling error to the productivity or abundance data generated by the population model. Sampling error was assumed to be lognormally distributed for all surveys. If $\mu$ and $\sigma$ were the mean and standard deviation on the nonlogarithmic scale, we set the logmean $=\ln \left(\mu^{2} / \sqrt{\sigma^{2}+\mu^{2}}\right.$ and the standard deviation $=\sqrt{\ln \left(1+\mathrm{CV}^{2}\right.}$ where $\mathrm{CV}=$ $\sigma / \mu$.

\section{Nest counts}

We simulated annual nest counts $\left(\gamma_{i j}\right)$ with the following equation:

$$
\gamma_{i j}=0.80 C_{i j} p_{i j} \varepsilon_{i j}
$$

where $i=$ simulation, $j=$ year,$C=$ the annual nest counts generated by the model (i.e. total breeding females $\times$ nests per female), 0.80 is the proportion of NW Atlantic DPS nesting that is in peninsular Florida (TEWG 2009), $p=$ the percent of Florida beaches surveyed by the Florida Index Nesting Beach Survey program and is uniformly distributed on [0.61, 0.79] (Witherington et al. 2009), and the errors $\varepsilon_{i j}$ were lognormally distributed with $\mu$ and $\sigma$ on the nonlogarithmic scale equal to 0.98 and 0.02 , respectively. The lognormal errors incorporate sampling error (missed nests, false crawls counted as nests, nests of other sea turtle species counted as loggerhead nests, etc.). We expect sampling error of about $2 \%$ (based on numbers in Witherington et al. 2009), with undercounting more common than overcounting, which is why $\mu$ was set to $<1$.

\section{Total adult females}

The actual count of adult females in the NW Atlantic DPS is not known but is typically extrapolated from nest counts using mean remigration interval and mean nests per female (Richards et al. 2011). We used the simulated samples of nest counts to extrapolate to total breeding females in the nesting population. Annual breeding females $\left(B F_{i j}\right)$ were equal to $\gamma_{i j} / 5$, where 5 is the mean nests per female
(Table 1), $i=$ simulation, and $j=$ year. To account for a mean remigration interval of $3 \mathrm{yr}$, we estimated total breeding females $\left(T F_{i j}\right)$ by taking 3 -year running sums of annual breeding females:

$$
T F_{i j, j \geq 3}=\sum_{j-2}^{j} B F_{i j}
$$

In estimating total adult females, clutch frequency and remigration interval were treated as fixed constants and assumed to have low interannual variability, although productivity parameters were stochastic in simulating loggerhead population changes over time.

\section{Aerial surveys}

We simulated abundance estimates as if they were derived from aerial survey data. We used the modelgenerated abundance, summed for stages 2-4, in neritic waters (to mimic what would be detected in an aerial survey) and applied lognormal sampling error based on uncertainty in real-world loggerhead abundance estimates from aerial surveys (NEFSC \& SEFSC 2011). Supplement 4 details the determination of the CVs for the lognormal sampling error associated with aerial surveys; NEFSC \& SEFSC (2011) reports quartiles rather than CVs for the abundance estimates that account for availability bias.

For the NN and NS regions separately, we simulated annual abundance estimates $\left(\phi_{i j}\right)$ for stages $2-4$ with the following equation:

$$
\phi_{i j}=\delta_{i j} \varepsilon_{i j}
$$

where $i=$ simulation, $j=$ year, $\delta=$ stage $2-4$ abundance as generated from the model, and the errors $\varepsilon_{i j}$ were lognormally distributed with $\mu$ on the nonlogarithmic scale equal to 1 and the CV on the nonlogarithmic scale equal to 0.34 for NN and 0.79 for NS.

We did post hoc simulations to explore the implications of detection and availability biases on abundance estimates from aerial surveys. We did a set of 200 simulations under the no-threat scenario in which aerial survey abundance estimates reflected a constant low bias or a time-varying bias (biased low for years 25-50 and biased high for years 51-75).

\section{Comparing population metrics}

Nest counts are monitoring breeding females (stage 4 from all regions) that get translated into total adult females based on clutch frequency and remi- 
gration interval assumptions, while aerial surveys are monitoring some portion of stages 2-4 in neritic waters (i.e. an aggregate measure over multiple stage classes). The monitoring metrics, then, are not directly comparable, and to acknowledge that disparity, we treated both abundance measures like relative abundance indices (i.e. used the monitoring metrics to infer information about population trend). In evaluating the 2 population metrics (total adult females, TF, extrapolated from nest counts and abundance estimates, $\phi$, from aerial surveys), we were interested in whether the metrics would detect and quantify similar population-level impacts from the various environmental and management scenarios, and whether changes in TF and $\phi$ were the same as those based on the true adult equivalents (i.e. estimated using the complete model-generated information). For both metrics, we computed the change from the no-impact scenario as $\left(y_{j k} / y_{j 0}\right)-1$, where $y=$ the annual value for the metric, $j=$ year, and $k=$ the impact scenario (where 0 equals no impact). We subtracted 1 from the ratio of impact to no impact so that a decrease from the no-impact scenario would be negative and an increase would be positive (e.g. a $20 \%$ decline in the metric as compared to the noimpact scenario would be reported as a percent change of -0.20 ).

To evaluate how close the trend for the population monitoring (nest counts or aerial surveys) was to that for adult equivalents (true measure of abundance), we compared the estimated population growth rates $\lambda$. For both metrics and for adult equivalents, we calculated $\lambda$ over the following year groups: $1-10,11-30$, $31-50,51-70$, and $71-100$. We estimated $\lambda$ as the geometric mean of the annual growth rates (derived from the sampled or simulated abundances) within each year group:

$$
\lambda_{i k}=\left(\prod_{s}^{e} \frac{y_{i j k}}{y_{i(j-1) k}}\right)^{\frac{1}{e-s+1}}
$$

where $y=$ the annual value for the metric, $i=$ simulation, $j=$ year, $k=$ the impact scenario, $s=$ the start year in the year group, and $e=$ the end year in the year group. For each year group and impact scenario, we plotted $\lambda$ calculated using each metric $\left(\lambda_{m}\right.$, where $m=$ metric) against $\lambda$ calculated using adult equivalents $\left(\lambda_{\mathrm{AE}}\right)$. We compared the $\lambda \mathrm{s}$ quantitatively using the median absolute relative error (MARE). Absolute relative error was calculated as $\left|\left(\lambda_{m}-\lambda_{\mathrm{AE}}\right) / \lambda_{\mathrm{AE}}\right|$. We then took the median across the 10000 replicate simulations.

We were also interested in differences between metrics when they were used to measure recovery criteria as laid out in the loggerhead recovery plan (NMFS \& USFWS 2008). The plan's demographic recovery criteria call for a particular annual rate of increase in nest counts over a generation time of $50 \mathrm{yr}$, and the plan indicates that increasing nests must correspond to increasing nesting females. The plan also includes criteria for in-water abundance, indicating a need for $95 \%$ statistical confidence that estimated inwater abundance is increasing over 1 generation time.

To align with the recovery criteria, we estimated the growth rate $(\lambda)$ for the 2 metrics and for simulated adult equivalents over a 50 yr time span beginning with the year at which we applied the impact scenarios (i.e. years 11-60). For all 3 measures, we also examined whether they corresponded to increasing nesting females by estimating the Pearson correlation coefficient between the metric and the total number of adult females from our model.

\section{RESULTS}

Adult females estimated from nest count sampling and abundances estimated from aerial surveys both showed long-term trends (Fig. 1) and long-term population growth rates (Table 4) that were similar to total simulated adult equivalents based on all model output. The trend in total simulated adult equivalents is consistent with a population in decline, with parameter values used in simulating the population dynamics based upon current literature values (SEFSC 2009, Hart et al. 2013). All metrics showed some deviations in estimated population trajectories across impact scenarios, with the greatest differences occurring with the scenarios of the rise of a new fishery that affected stage 2-4 turtles and a new threat to stage 1 turtles.

Differences between nest monitoring and aerial surveys were more apparent when viewing the results as the predicted level of impact compared to that for adult equivalents. Nest surveys showed a 20-30 yr lag in detecting a population response for the new threat to stage 1 scenario, while aerial surveys showed similar or somewhat lower impacts and similar timing as adult equivalents (Fig. 2: upper right panel, green line compared to orange and black lines). Nest counts also underestimated the impact if females began laying more nests per season, which could, for example, be caused by an environmental change resulting in better foraging (Fig. 2: lower center panel). In contrast, nest surveys also showed deviation, but as an overestimate of the impact, if adult 


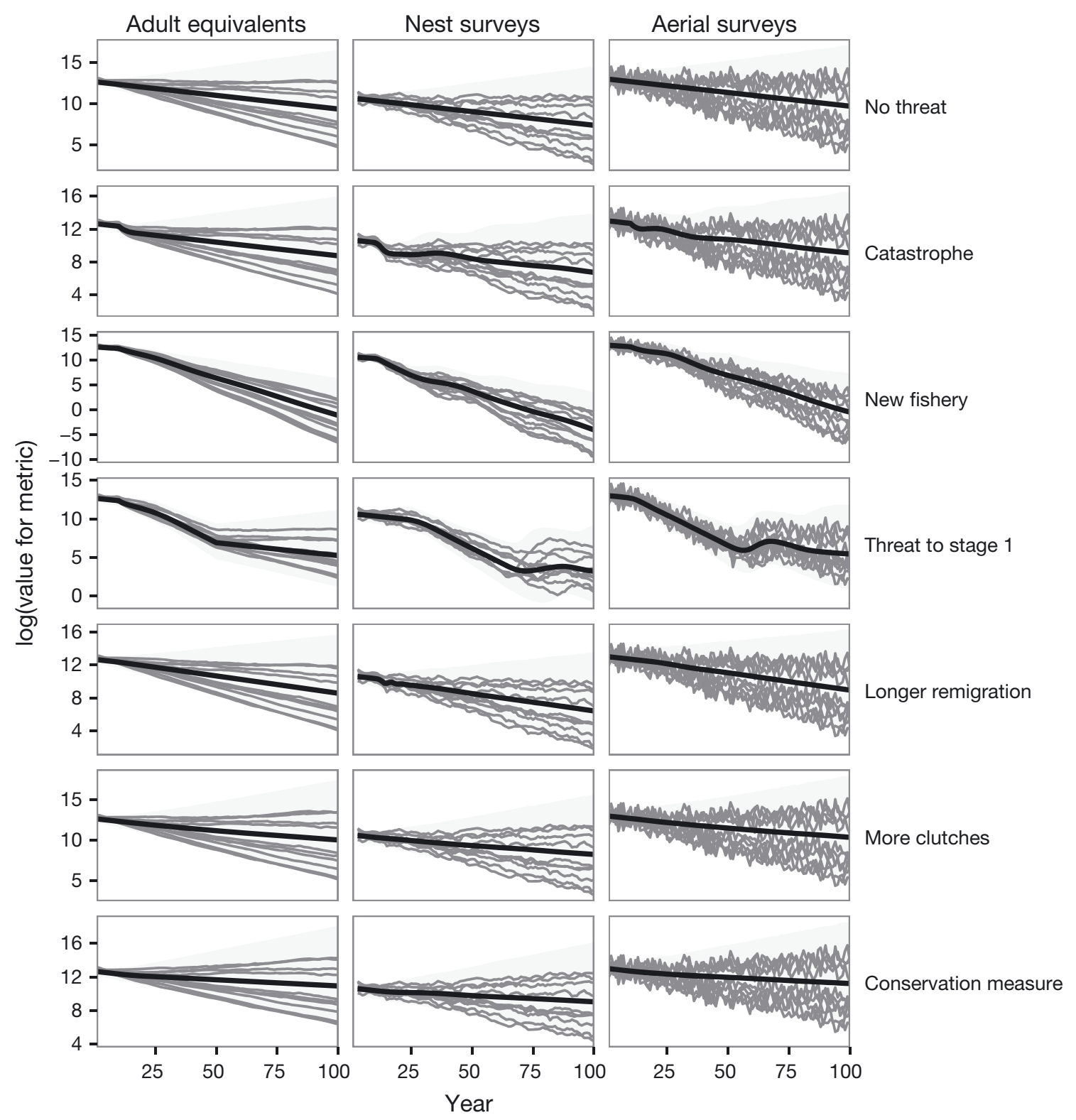

Fig. 1. Trends in simulated total adult equivalents and population-monitoring metrics (total adult females estimated from nest surveys and abundance estimated from aerial surveys). Black line is the mean; gray lines are example trajectories from 10 simulations, gray shading encompasses $95 \%$ of simulations

females had longer remigration intervals (perhaps if foraging were poor in some years) (Fig. 2: lower left panel). Aerial surveys also differed from adult equivalents if females had longer remigration intervals, with a lag of about $20 \mathrm{yr}$ before picking up a population decline. Both nesting and aerial surveys showed out-of-phase cycles in the impact of a catastrophic event, while adult equivalents simply showed a sharp initial decline leading to a constant level of impact (Fig. 2: top left panel).

In general, nesting and aerial monitoring metrics generated similar mean population growth rates over long time spans (Table 4), though the variation in aerial survey estimates, especially over short time spans, exceeded that for adult equivalents and nesting surveys (Fig. 3). With no population impact applied, the mean population growth rate $\lambda$ was 0.97 across all year groups for all 3 metrics (Fig. 3). For all 3 metrics, $\lambda$ decreased only slightly with a longer remigration interval ( 0.96), and increased slightly with more clutches being laid ( 0.98) and with the conservation measure scenario ( 0.99). Moderate changes in growth rates were predicted for the catastrophe scenario, with $\lambda$ reduced to $0.93-0.94$ for the 
Table 4. Mean population measures $50 \mathrm{yr}$ after start of impact scenario (year 11). Population growth rate $(\lambda)$ reflects the 50 yr trend. Correlation $(\rho)$ with total adult females from simulated population over 50 yr shown for total adult females estimated from nest counts and abundance estimates from aerial surveys. $95 \%$ of simulations were in the interval in parentheses. $\mathrm{AE}=$ adult equivalents

\begin{tabular}{|c|c|c|c|c|c|}
\hline \multirow[b]{2}{*}{ Impact scenario } & \multirow{2}{*}{$\begin{array}{c}\mathrm{AE}- \\
\lambda\end{array}$} & \multicolumn{2}{|c|}{-Total females (est.) } & \multicolumn{2}{|c|}{ Aerial surveys } \\
\hline & & $\lambda$ & $\rho$ (total adults) & $\lambda$ & $\rho$ (total adults) \\
\hline None & $0.97(0.92,1.04)$ & $0.97(0.92,1.04)$ & $0.94(0.64,1.00)$ & $0.97(0.91,1.05)$ & $0.54(-0.09,0.86)$ \\
\hline Catastrophe & $0.96(0.91,1.03)$ & $0.95(0.91,1.03)$ & $0.95(0.84,0.99)$ & $0.96(0.90,1.03)$ & $0.41(-0.30,0.86)$ \\
\hline New fishery & $0.86(0.82,0.93)$ & $0.85(0.80,0.92)$ & $0.99(0.98,1.00)$ & $0.87(0.81,0.94)$ & $0.69(0.38,0.92)$ \\
\hline Threat to stage 1 & $0.89(0.86,0.94)$ & $0.89(0.85,0.93)$ & $0.99(0.97,1.00)$ & $0.88(0.83,0.95)$ & $0.71(0.43,0.88)$ \\
\hline More clutches & $0.97(0.93,1.05)$ & $0.98(0.93,1.05)$ & $0.91(0.38,0.99)$ & $0.97(0.91,1.06)$ & $0.53(-0.10,0.85)$ \\
\hline Longer remigration & $0.96(0.92,1.03)$ & $0.96(0.91,1.03)$ & $0.93(0.65,0.99)$ & $0.96(0.90,1.04)$ & $0.57(-0.10,0.87)$ \\
\hline Conservation measure & $0.98(0.94,1.06)$ & $0.99(0.94,1.06)$ & $0.93(0.61,0.99)$ & $0.98(0.92,1.06)$ & $0.47(-0.14,0.82)$ \\
\hline
\end{tabular}

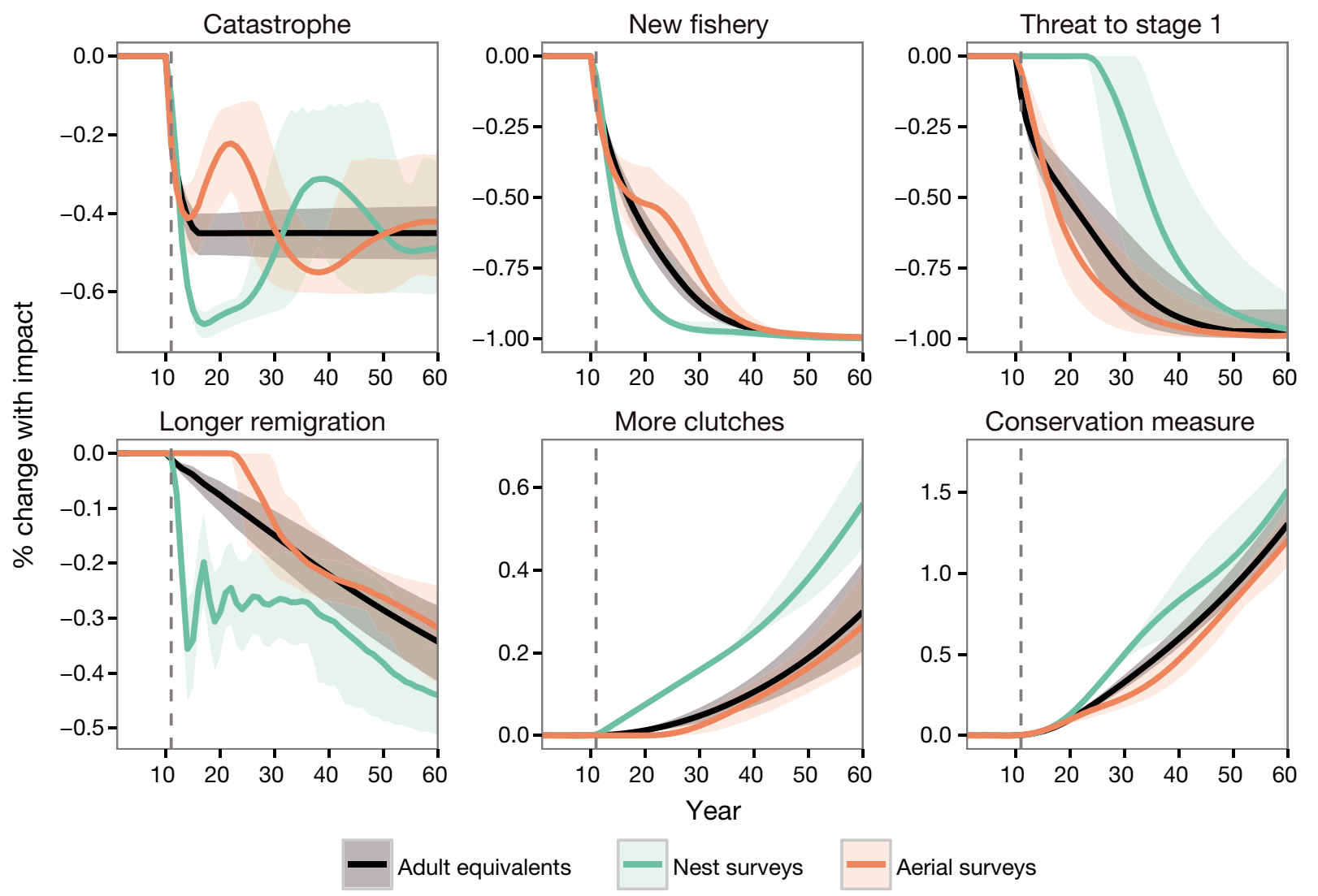

Fig. 2. Percent change for impact scenarios compared to no impact. Negative values indicate a decline; positive values indicate an increase (e.g. value of -0.25 indicates $25 \%$ decline in the metric compared to no impact). Shading encompasses $95 \%$ of simulations, with the solid line denoting the average. Vertical dashed line indicates the start of impact scenarios (i.e. year 11). The change in the 2 monitoring metrics (adult females estimated from nest surveys and abundance estimated from aerial surveys) can be compared to the change for adult equivalents

year group 11-30 and then returning to around 0.97 for the rest of the time period. Large changes in $\lambda$ were predicted under the new fishery scenario; $\lambda$ decreased to $<0.9$ for all 3 metrics, with $\lambda$ for the 2 monitoring metrics sometimes higher and sometimes lower than $\lambda$ for adult equivalents. Under the threat to stage 1 scenario, large changes were also pre- dicted; $\lambda$ for adult equivalents decreased to 0.85 by years $31-50$, then returned to 0.97 . Aerial surveys produced $\lambda$ that tracked fairly well with $\lambda$ from adult equivalents (except that it overestimated in years 51-70); adult females estimated from nest counts overestimated $\lambda$ in early years, underestimated $\lambda$ for years 51-70, and overestimated for years 71-100. 


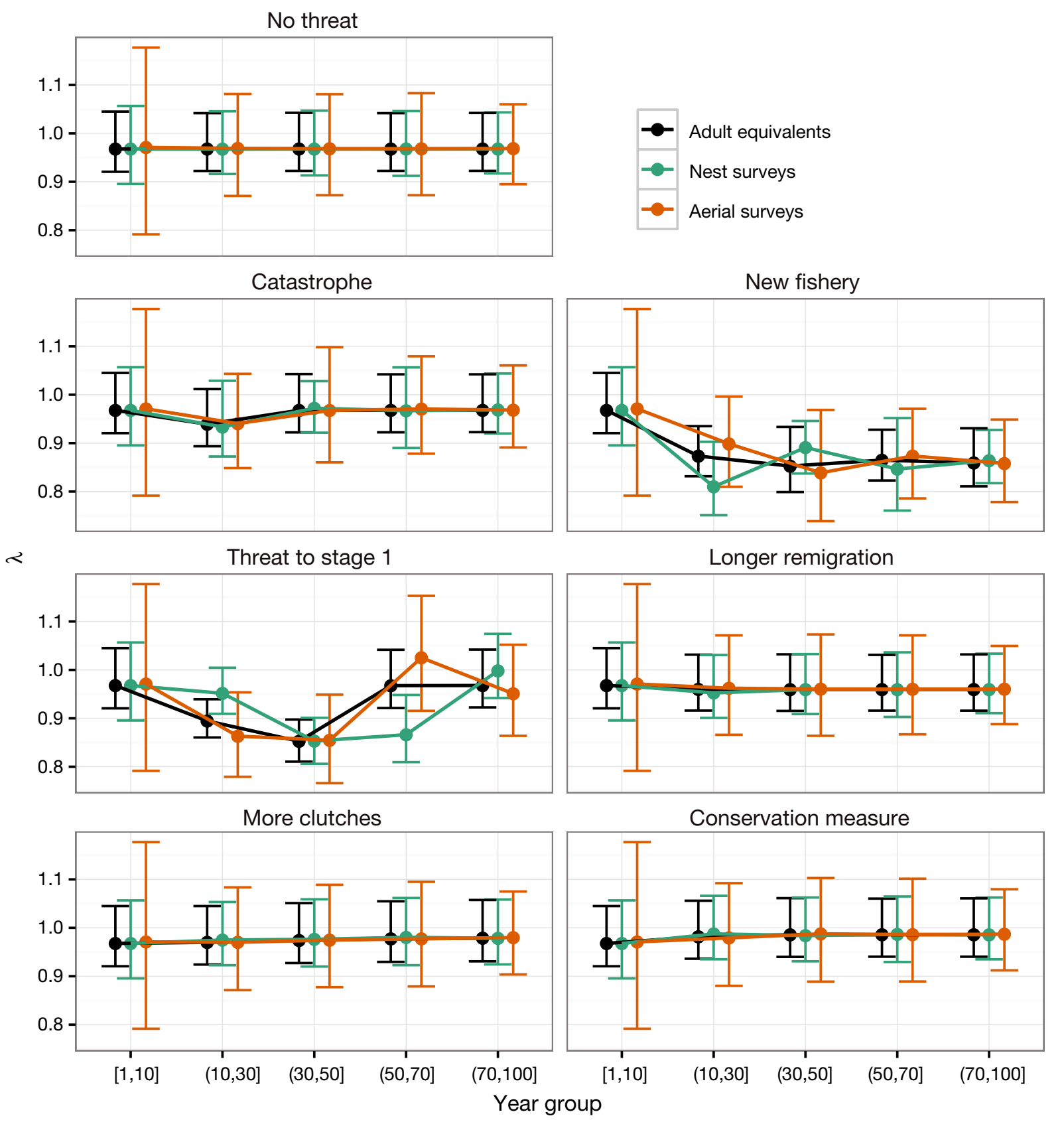

Fig. 3. Mean population growth rate $(\lambda)$ as estimated over year groups for adult equivalents and 2 population-monitoring metrics (adult females estimated from nest surveys and abundance estimated from aerial surveys). Error bars encompass $95 \%$ of simulations. Bracket notation for year groups: [1, 10] indicates 1 to 10 inclusively, while $(10,30]$ indicates $>10$ up to and including 30

The estimated population growth rates over discrete time intervals were more closely related to growth rates based on modeled adult equivalents when the nest count metric was used rather than the aerial survey metric. Plotting $\lambda$ as calculated from the population monitoring metrics against $\lambda$ as calculated from adult equivalents $\left(\lambda_{\mathrm{AE}}\right)$ (Fig. 4 ) showed that $\lambda$ for adult females estimated from nest counts generally had the same range as $\lambda_{\mathrm{AE}}$, while $\lambda$ for abundance estimated from aerial surveys had a greater range than $\lambda_{\mathrm{AE}}$. Scenarios with low values of $\lambda_{\mathrm{AE}}$ tended to have even lower values of $\lambda$ estimated by aerial surveys, and similarly for high values, resulting in a slope of $\lambda$ against $\lambda_{\mathrm{AE}}$ that was far from 1 (dotted line in Fig. 4 has slope of 1). The lines for $\lambda$ from the estimated adult females generally have slopes close to 1 , 


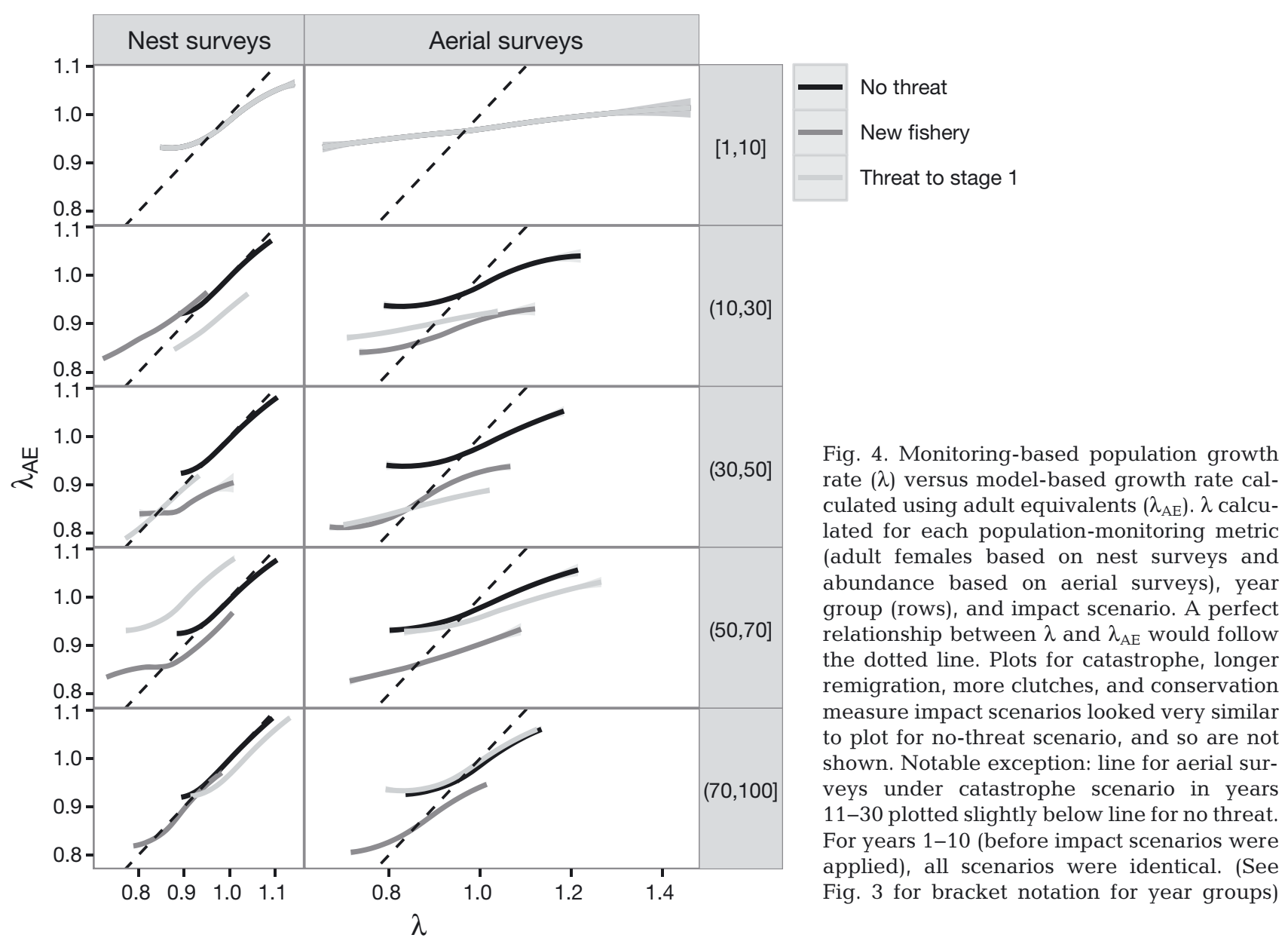

although $\lambda$ was sometimes higher than $\lambda_{\mathrm{AE}}$ (right of the dotted line in Fig. 4) or lower than $\lambda_{\mathrm{AE}}$ (left of the dotted line). Adult females estimated from nest counts also had high average correlations with the simulated total adult females from the model output (Table 4), which satisfies the demographic criteria of the loggerhead recovery plan.

Adult females estimated from nest counts had lower MARE for $\lambda$ versus $\lambda_{\mathrm{AE}}$ than did aerial surveys for all year groups in all but 2 impact scenarios (Fig. 5). Under the new fishery and threat to stage 1 scenarios, MARE for aerial survey abundance estimates was lower for 3 out of the 4 year groups after impacts were applied in year 11 .

\section{DISCUSSION}

Our simulations indicated that neither nest nor aerial monitoring alone provided sufficient information when viewed across a suite of likely impact scenarios. Our results suggest that adult female abundance estimated from nest counts or total abundance esti- mated from aerial surveys are likely to work equally well as monitoring schemes if the goal is to estimate long-term (e.g. $20 \mathrm{yr}$ or more) population trend, or if the population is at a stable age distribution and the population structure is not likely to undergo dynamic changes as a result of environmental or anthropogenic impacts.

If the goal is to monitor impacts over shorter time frames (e.g. 3 to $5 \mathrm{yr}$ ) or to monitor impacts that may disrupt stable age distribution, then neither of the metrics that we examined was entirely suitable on its own. Neither metric could be counted on to reliably, consistently, and accurately detect population-level impacts across all simulated threat scenarios. Both metrics sometimes overestimated and sometimes underestimated impact as compared to the impact on the true total adult equivalent turtles.

Using adult females based on nest counts as a monitoring metric has advantages over in-water aerial surveys. The estimated number of adult females based on nest counts is expected to have less uncertainty than aerial survey abundance estimates (Fig. 3), and estimated adult females often had a closer rela- 


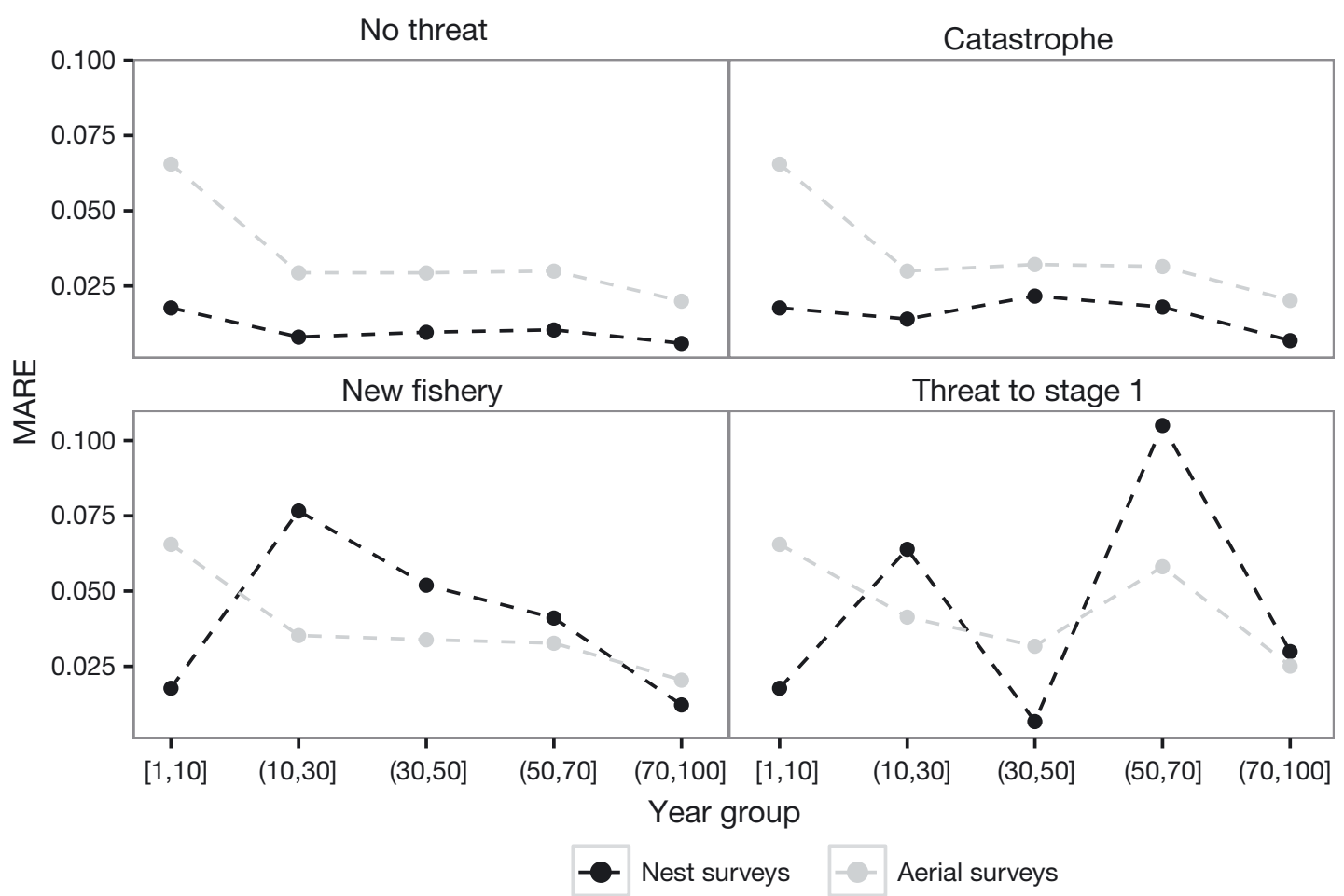

Fig. 5. Median absolute relative error (MARE) for population growth rate ( $\lambda$ ) calculated from population-monitoring metrics (adult females based on nest surveys or abundance based on aerial surveys) compared to $\lambda$ calculated from adult equivalents. MARE calculated by year group and impact scenario. Three impact scenarios not shown (longer remigration interval, more clutches per female, and conservation measure) showed no obvious differences from no-threat scenario. (See Fig. 3 for bracket notation for year groups)

tionship to adult equivalents. The close relationship between adult females and adult equivalents could be an artifact of treating clutch frequency and remigration interval as fixed constants when estimating total adult females, with values close to the mean values used in simulating the population dynamics. Obtaining data on nesting is also less expensive and potentially has less of an impact on the environment. Research indicates that comprehensive monitoring of entire nesting seasons may not even be necessary to achieve the same power to detect population trends as a more limited sampling design can achieve (Sims et al. 2008, Whiting et al. 2013); thus, it may be possible to even further reduce the required resources for nesting beach monitoring, particularly for start-up programs. Aerial surveys had some advantages over nest counts, particularly when the effect of an impact scenario had a time lag, for example, when stage 1 survival was lowered under the threat to stage 1 scenario. Sea turtles are long-lived, slow-growing animals that may not reach breeding age for $30 \mathrm{yr}$ (30 is the mean age to maturity in the current model). Thus, if the youngest turtles are affected by an anthropogenic or environmental threat, it might not be noticed for 20 to $30 \mathrm{yr}$ (when the affected cohort reaches breeding age) if researchers were monitoring only nest counts. However, aerial surveys were not fully immune to impact scenarios with time lags, as evident in the longer remigration interval scenario. As remigration intervals increase, overall productivity will decline, and this will not become apparent until the affected cohort reaches stage 2 roughly 10 to 20 yr later (13 is the mean stage duration for stage 1). Nest counts were able to pick up the decline in productivity as a result of longer remigration intervals, with aerial surveys more closely tracking adult equivalents after several years. Abundance estimates from in-water aerial surveys and nest counts could be improved by finding ways to decrease the variance, identify biases, and decrease costs.

For the current simulations, not all sources of variability and bias for either population-monitoring scheme could be explicitly included in generating the simulated population metrics. Nest count data, for instance, are subject to variability in observer experience, length of survey season, washout from storms, site fidelity (i.e. turtles nesting on the surveyed beaches in some seasons, or at some point within the season, and nesting outside the surveyed beaches at other times), and assumptions regarding 
clutch frequency and remigration interval to extrapolate to total adult females. Aerial survey data are subject to observer experience, visibility (sea state and turbidity), seasonal distributions of animals, and availability of animals (i.e. time spent at the surface). Aerial surveys would also need to consider assumptions about sex ratio and potential differences in detection rates by gender. All of these sources of variability are wrapped into annual sampling error in the current simulation analysis using the population model. Also, future aerial surveys might not be conducted every year as in the current model. The situation represented by the current model may be a 'best-case' scenario if future monitoring is not as frequent, precise, or unbiased as described by the current model.

Accounting for availability bias is crucial for robust sea turtle abundance estimates. Post hoc simulations showed that under conditions of constant low bias, we would likely reach similar conclusions about population trend as we would from unbiased aerial survey abundance estimates (Fig. 6: green lines), but if bias varied over time, it could affect our interpretation of population trend (Fig. 6: orange lines) (Rudd \& Branch 2017).

For population monitoring of sea turtles, surveying the nesting beaches in peninsular Florida may be more straightforward and less resource-intensive than flying line transect surveys along the entire US east coast, and it may be sufficient for evaluating whether long-term recovery has been achieved (although the formal recovery plan also requires inwater monitoring). Our current research shows the value of nest count data, but also some caveats on relying solely on nest counts to infer loggerhead population trends, especially for short-term applications. Given the high costs and sources of high uncertainty for obtaining estimates of total abundance, future research might evaluate whether there are other abundance metrics or even non-abundance metrics that might be useful for population monitoring of sea turtles. Here we focused on existing data and assessment approaches, but we acknowledge the need for more comprehensive evaluations of a broader array of monitoring approaches, which could include dedicated mark-recapture programs to assess abundance, size class distribution, sex ratio, survival, movement, and other demographic parameters. In conclusion, neither nesting beach monitoring nor inwater aerial surveys alone adequately monitored the simulated population-level impact on the time scales relevant to ESA Section 7 consultations (typically short-term) as well as the loggerhead recovery plan

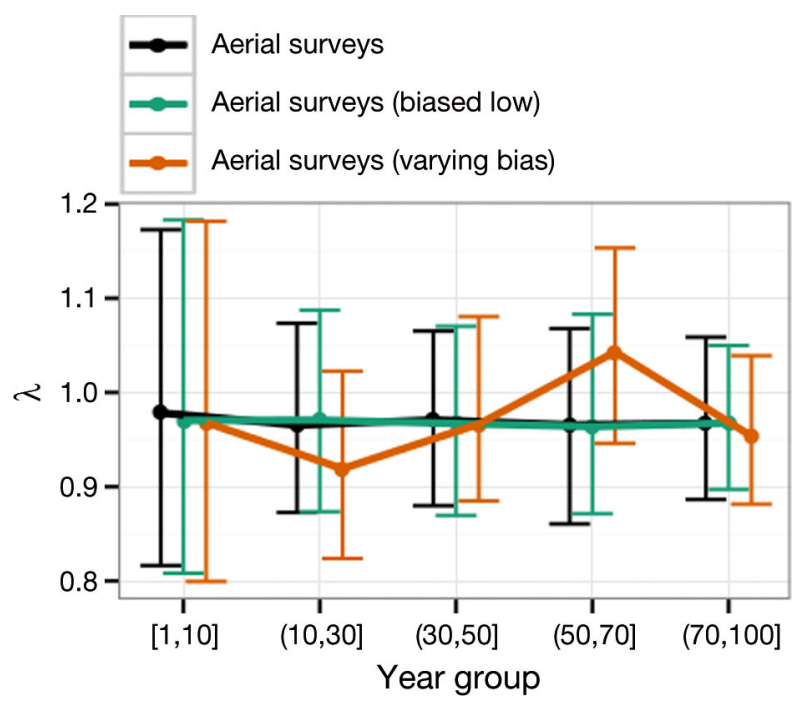

Fig. 6. Mean population growth rate $(\lambda)$ estimated over year groups under no-threat scenario. Abundance estimated from aerial surveys was used to estimate $\lambda$, and sampling had either no bias, constant low bias, or time-varying bias (biased low for years 25-50 and biased high for years 51-75). Error bars encompass $95 \%$ of simulations. (See Fig. 3 for bracket notation for year groups)

(typically long-term). As quantitative assessments of population-level impacts (Curtis \& Moore 2013, Curtis et al. 2015) are developed and refined, the selection of monitoring metrics should be evaluated to ensure the metric can detect impacts at the scale of interest. Given the current methods for loggerhead abundance surveys, the best detection of short-term impacts may result from monitoring both beach and marine datasets.

Acknowledgements. We thank D. Palka and D. Sigourney for advice on simulating aerial survey data, and C. Upite for reviewing the manuscript prior to submission. We also thank 3 anonymous reviewers.

\section{LITERATURE CITED}

Anderson DR (2001) The need to get the basics right in wildlife field studies. Wildl Soc Bull 29:1294-1297

Bart J, Droege S, Geissler P, Peterjohn B, Ralph CJ (2004) Density estimation in wildlife surveys. Wildl Soc Bull 32: 1242-1247

Bjorndal KA, Bolten AB, Lagueux CJ (1994) Ingestion of marine debris by juvenile sea turtles in coastal Florida habitats. Mar Pollut Bull 28:154-158

* Bjorndal KA, Bowen BW, Chaloupka M, Crowder LB and others (2011) Better science needed for restoration in the Gulf of Mexico. Science 331:537-538

* Borchers DL, Langrock R (2015) Double-observer line transect surveys with Markov-modulated Poisson process models for animal availability. Biometrics 71:1060-1069 
Borchers DL, Zucchini W, Heide-Jørgensen MP, Cañadas A, Langrock R (2013) Using hidden Markov models to deal with availability bias on line transect surveys: line transect availability bias. Biometrics 69:703-713

Bovery CM, Wyneken J (2015) Seasonal variation in sea turtle density and abundance in the southeast Florida Current and surrounding waters. PLOS ONE 10:e0145980

Buckland ST, Anderson DR, Burnham KP, Laake JL, Borchers DL, Thomas L (2001) Introduction to distance sampling: estimating abundance of biological populations. Oxford University Press, Oxford

Carr A, Carr MH, Meylan AB (1978) The ecology and migrations of sea turtles, 7 . The West Caribbean green turtle colony. Bull Am Mus Nat Hist 162:1

Caswell H (2001) Matrix population models. Construction, analysis, and interpretation. Sinauer, Sunderland, MA

Chaloupka M (2003) Stochastic simulation modeling of loggerhead population dynamics given exposure to competing mortality risks in the western South Pacific. In: Bolten $\mathrm{AB}$, Witherington $\mathrm{BE}$ (eds) Loggerhead sea turtles. Smithsonian Books, Washington, DC, p 274-294

* Chaloupka M, Limpus C (2001) Trends in the abundance of sea turtles resident in southern Great Barrier Reef waters. Biol Conserv 102:235-249

Curtis R, Hicks RL (2000) The cost of sea turtle preservation: the case of Hawaii's pelagic longliners. Am J Agric Econ 82:1191-1197

* Curtis KA, Moore JE (2013) Calculating reference points for anthropogenic mortality of marine turtles. Aquat Conserv 23:441-459

Curtis KA, Moore JE, Benson SR (2015) Estimating limit reference points for Western Pacific leatherback turtles (Dermochelys coriacea) in the U.S. West Coast EEZ. PLOS ONE 10:e0136452

* Ehrhart L, Redfoot W, Bagley D, Mansfield K (2014) Longterm trends in loggerhead (Caretta Caretta) nesting and reproductive success at an important western Atlantic rookery. Chelonian Conserv Biol 13:173-181

Engeman R (2003) More on the need to get the basics right: population indices. Wildl Soc Bull 31:286-287

Epperly SP, Braun J, Chester AJ (1995) Aerial surveys for sea turtles in North Carolina inshore waters. Fish Bull 93: 254-261

Finkbeiner EM, Wallace BP, Moore JE, Lewison RL, Crowder LB, Read AJ (2011) Cumulative estimates of sea turtle bycatch and mortality in USA fisheries between 1990 and 2007. Biol Conserv 144:2719-2727

Fish MR, Côté IM, Gill JA, Jones AP, Renshoff S, Watkinson AR (2005) Predicting the impact of sea-level rise on Caribbean sea turtle nesting habitat. Conserv Biol 19:482-491

Fisher RA (1930) The genetical theory of natural selection. Clarendon Press, Oxford

Frey A, Dutton P, Shaver D, Walker J, Rubio C (2014) Kemp's ridley Lepidochelys kempii nesting abundance in Texas, USA: a novel approach using genetics to improve population census. Endang Species Res 23:63-71

Haas HL (2010) Using observed interactions between sea turtles and commercial bottom-trawling vessels to evaluate the conservation value of trawl gear modifications. Mar Coast Fish 2:263-276

Hart KM, Lamont MM, Sartain AR, Fujisaki I, Stephens BS (2013) Movements and habitat-use of loggerhead sea turtles in the northern Gulf of Mexico during the reproductive period. PLOS ONE 8:e66921

Hawkes LA, Broderick AC, Coyne MS, Godfrey MH, Godley
BJ (2007) Only some like it hot-quantifying the environmental niche of the loggerhead sea turtle. Divers Distrib 13:447-457

*Heppell SS (2005) Development of alternative quantitative tools to assist in jeopardy evaluation for sea turtles. Report for the Southeast Fisheries Science Center. Requisition number NFFN7020-3-00225. www.sefsc.noaa.gov/ turtledocs/CR_Heppell_2005_Quantitative_Tools.pdf

Laake JL, Borchers DL (2004) Methods for incomplete detection at distance zero. In: Buckland ST, Andersen DR, Burnham KP, Laake JL, Thomas L (eds) Advanced distance sampling. Oxford University Press, New York, NY, p 108-189

* Lande R, Orzack SH (1988) Extinction dynamics of agestructured populations in a fluctuating environment. Proc Natl Acad Sci USA 85:7418-7421

K Lauriano G, Panigada S, Casale P, Pierantonio N, Donovan GP (2011) Aerial survey abundance estimates of the loggerhead sea turtle Caretta caretta in the Pelagos Sanctuary, northwestern Mediterranean Sea. Mar Ecol Prog Ser 437:291-302

*Magnusson GM, Bisack KD, Milliken HO (2012) The costeffectiveness of gear research relative to a closure: pound nets and sea turtles as an example. US Dept Commerce, Northeast Fish Sci Cent Ref Doc 12-01. National Marine Fisheries Service, Woods Hole, MA. www.nefsc. noaa.gov/nefsc/publications/

Mansfield K (2006) Sources of mortality, movements and behavior of sea turtles in Virginia. PhD dissertation, The College of William and Mary, Williamsburg, VA

Marsh H, Sinclair DF (1989) Correcting for visibility bias in strip transect aerial surveys of aquatic fauna. J Wildl Manag 53:1017-1024

Morris WF, Doak DF (2002) Quantitative conservation biology. Sinauer, Sunderland, MA

*Murray KT (2015) The importance of location and operational fishing factors in estimating and reducing loggerhead turtle (Caretta caretta) interactions in U.S. bottom trawl gear. Fish Res 172:440-451

NEFSC \& SEFSC (Northeast Fisheries Science Center \& Southeast Fisheries Science Center) (2011) Preliminary summer 2010 regional abundance estimate of loggerhead turtles (Caretta caretta) in the Northwestern Atlantic Ocean continental shelf waters. US Dept Commerce, NEFSC Ref Doc 11-03. National Marine Fisheries Service, Woods Hole, MA. www.nefsc.noaa.gov/nefsc/ publications

NMFS \& USFWS (National Marine Fisheries Service \& US Fish and Wildlife Service) (2008) Recovery plan for the Northwest Atlantic population of loggerhead sea turtle (Caretta caretta), 2nd revision. NMFS, Silver Spring, MD

Piacenza SE, Balazs GH, Hargrove SK, Richards PM, Heppell SS (2016) Trends and variability in demographic indicators of a recovering population of green sea turtles Chelonis mydas. Endang Species Res 31:103-117

Richards PM, Epperly SP, Heppell SS, King RT and others (2011) Sea turtle population estimates incorporating uncertainty: a new approach applied to western North Atlantic loggerheads Caretta caretta. Endang Species Res 15:151-158

Rudd MB, Branch TA (2017) Does unreported catch lead to overfishing? Fish Fish 18:313-323

SEFSC (Southeast Fisheries Science Center) (2009) An assessment of loggerhead sea turtles to estimate 
impacts of mortality reductions on population dynamics. National Marine Fisheries Service, SEFSC, Contrib PRD-08/09-14

Seminoff JA, Allen CD, Balazs GH, Dutton PH and others (2015) Status review of the green turtle (Chelonia mydas) under the U.S. Endangered Species Act. NOAA Tech Memo NOAA-NMFS-SWFSC-539

Sims M, Wanless S, Harris MP, Mitchell PI, Elston DA (2006) Evaluating the power of monitoring plot designs for detecting long-term trends in the numbers of common guillemots. J Appl Ecol 43:537-546

Sims M, Bjorkland R, Mason P, Crowder LB (2008) Statistical power and sea turtle nesting beach surveys: How long and when? Biol Conserv 141:2921-2931

Snover ML, Heppell SS (2009) Application of diffusion approximation for risk assessments of sea turtle populations. Ecol Appl 19:774-785

TEWG (Turtle Expert Working Group) (1998) An assessment of the Kemp's ridley (Lepidochelys kempii) and loggerhead (Caretta caretta) sea turtle populations in the western North Atlantic. US Dept Commerce, NOAA Tech Memo NMFS-SEFSC-409

TEWG (2000) Assessment update for the Kemp's ridley and loggerhead sea turtle populations in the Western North Atlantic. US Dept Commerce, NOAA Tech Memo NMFS-SEFSC-444

TEWG (2009) An assessment of the loggerhead turtle population in the western North Atlantic Ocean. US Dept Commerce, NOAA Tech Memo NMFS-SEFSC-575

Thompson NB (1986) A summary of marine turtle sightings from NMFS/SEFC aerial census surveys for cetaceans and turtles in the Gulf of Mexico, 1983-1986. National Marine Fisheries Service, Miami Laboratory Coastal Fishery Resources Division, Miami, FL

Editorial responsibility: Brendan Godley, University of Exeter, Cornwall Campus, UK
Thompson WL (2002) Towards reliable bird surveys: accounting for individuals present but not detected. Auk 119:18-25

Thomson JA, Cooper AB, Burkholder DA, Heithaus MR, Dill LM (2012) Heterogeneous patterns of availability for detection during visual surveys: spatiotemporal variation in sea turtle dive-surfacing behaviour on a feeding ground. Methods Ecol Evol 3:378-387

Thomson JA, Cooper AB, Burkholder DA, Heithaus MR, Dill LM (2013) Correcting for heterogeneous availability bias in surveys of long-diving marine turtles. Biol Conserv 165:154-161

Troגng S, Chaloupka M (2007) Variation in adult annual survival probability and remigration intervals of sea turtles. Mar Biol 151:1721-1730

Wallace BP, Heppell SS, Lewison RL, Kelez S, Crowder LB (2008) Impacts of fisheries bycatch on loggerhead turtles worldwide inferred from reproductive value analyses. J Appl Ecol 45:1076-1085

*Warden ML, Haas HL, Rose KA, Richards PM (2015) A spatially explicit population model of simulated fisheries impact on loggerhead sea turtles (Caretta caretta) in the Northwest Atlantic Ocean. Ecol Modell 299:23-39

Whiting AU, Chaloupka M, Limpus CJ (2013) Comparing sampling effort and errors in abundance estimates between short and protracted nesting seasons for sea turtles. J Exp Mar Biol Ecol 449:165-170

*Whiting AU, Chaloupka M, Pilcher N, Basintal P, Limpus CJ (2014) Comparison and review of models describing sea turtle nesting abundance. Mar Ecol Prog Ser 508: 233-246

* Witherington B, Kubilis P, Brost B, Meylan A (2009) Decreasing annual nest counts in a globally important loggerhead sea turtle population. Ecol Appl 19:30-54

Submitted: November 23, 2016; Accepted: August 8, 2017 Proofs received from author(s): October 31, 2017 